http://ejtr.vumk.eu

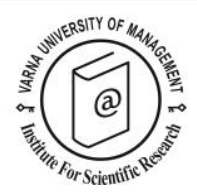

\title{
Diving into the consequences of stakeholders unheard
}

\author{
Marco Scholtz ${ }^{1 *}$ and Melville Saayman ${ }^{2}$
}

Received: 29/03/2018 Accepted: 24/06/2018

\footnotetext{
1 Tourism Research in Economics, Environs \& Society - North-West University, Potchefstroom, South Africa. E-mail: Marco.Scholtz@nwu.ac.za Mail: Box 204, Building E3, Potchefstroom Campus, Private Bag X6001, Potchefstroom, South Africa.

${ }^{2}$ Tourism Research in Economics, Environs \& Society - North-West University, Potchefstroom, South Africa. Email: Melville.Saayman@nwu.ac.za

* Corresponding author
}

\begin{abstract}
The positive sentiment, as well as the role of the residents as a key stakeholder in the scuba diving tourism system (SDTS) in Italy's Portofino Marine Protected area (PMPA), is essential for the sustainability of the SDTS. However, studies on this area found that residents did not form part of the planning and the implementation of the MPA or SDTS, and as a result, negativity towards these industries was observed. It was the purpose of this study to determine possible gaps in communication and understanding between two key stakeholders in this SDTS, namely the residents and the dive operators in order to create better undertstanding and resident sentiment towards the industry. This was done through a mixed-method approach. Interviews were held with dive operators, after which a questionnaire was distributed to residents. From the results, misperceptions and miscommunication were found between the two stakeholders which caused negativity in the SDTS. The data showed that residents are not aware that they are stakeholders with an essential role in the SDTS. This study contributes to current literature regarding the importance of residents as stakeholders in SDTSs and the tourism industry as a whole, and the manner in which negative social impact perceptions can foster negativity towards tourism activities. From a practical perspective, this study makes recommendations on how systems such as the PMPA and SDTS should be planned and managed by incorporating the key stakeholders into the planning and implementation, thereby bridging the gaps in communication and understanding between the stakeholders, and building a more sustainable tourism industry.
\end{abstract}

(C) 2018 Varna University of Management. All rights reserved

Keywords: dive operators, marine protected area, marine tourism, residents, scuba diving, social impact, stakeholders

Citation: Scholtz, M., M. Saayman (2018) Diving into the consequences of stakeholders unheard. European Journal of Tourism Research 20, pp. 105-124

\section{Introduction}

Marine tourism is a rapidly expanding sector of the global tourism industry (Jennings, 2004; Moskwa, 2012). This industry sector includes leisure and recreational activities that predominantly occur in the coastal zone as well as coastal waters that are saline in nature (Hall, 2001). Some of the more popular coastal activities include kayaking, fishing, snorkelling, surfing and scuba diving (Garrod \& Wilson, 
2003). Scuba (or self-contained underwater breathing apparatus) diving has demonstrated significant growth and development, especially in recent times (Geldenhuys, Van der Merwe \& Slabbert, 2014). In 2015, over 25 million certified divers, spread over 200 countries and territories, were recorded by the Professional Association of Diving Instructors (PADI), with an average growth rate of 900000 additional diver certifications annually (PADI, 2016). The scuba diving industry, in line with the growth in certified diver numbers, has developed into a multi-billion dollar industry that includes dive products and equipment, scuba diving schools and scuba dive operators (hereafter referred to as dive operators), as well as all forms of tourism services and products such as travel, accommodation and catering (Dimmock, Cummins \& Musa, 2013). Given the global scale of the scuba diving activity, it is inevitable that it will generate various forms of impacts on the stakeholders where it takes place (Mason, 2015).

Musa and Dimmock (2017) proposed the scuba diving tourism system (SDTS) to understand the various stakeholders in the tourism industry better. According to the authors, the SDTS includes critical stakeholders such as the scuba divers (demand), the dive operators and charters (supply), the marine environment itself (inclusive of Marine Protected Areas [MPAs]), dive certification agencies (who ensure that divers are educated on diving), government regulatory bodies (who enact laws which regulate the SDTS) and the host community (who lives within the MPA and interacts with the SDTS daily). Each stakeholder plays a role in the sustainability of marine environments through collaboration and the exchange of ideas. When managing an SDTS, it is essential to take all stakeholders into account when measuring and the impacts of marine tourism. The three main topics of tourism impact research include social, ecological and economic impact studies (Fennell, 2015). It is vital that all the impacts of tourism be managed appropriately to ensure the sustainability of the tourism industry. However, it has been argued that significantly more emphasis be placed on the management and protection of the ecological features of a marine area as well as the scuba diving industry (Abidin \& Mohamed,
2014; Hillmer-Pegram, 2014), whereas less attention is paid to the residents within such an SDTS (Musa \& Dimmock, 2017; Mascia et al., 2010; Padock, 2006).

A failure to engage with residents is problematic as the successful operation and sustainability of the tourism industry are heavily dependent on the goodwill of the residents who occupy the areas in which the tourism activities take place (Jurowski \& Gursoy, 2004; Kuvan \& Akan, 2005; Park, Lee, Choi \& Yoon, 2012). It is furthermore possible for residents to be stakeholders in SDTSs, by holding positions such as MPA management, local councils, business owners, suppliers and employees, as well as community residents who are not directly involved in the scuba diving industry (Freeman, 2014). Regarding the scuba diving industry, dive instructors and dive charters act as one stakeholder in the industry, whereas the local community who provides accommodation, restaurants, shops and other services is another form of stakeholder. The tourism industry will exude social impacts on the residents, which will determine their perceptions and feelings towards the industry, while the dive operators will have to endure other residents' reactions towards the industry (Godfrey \& Clarke, 2007).

With MPAs often not keeping the residents' interests in mind or not always understanding their role as stakeholders in the MPA or SDTS (Mascia et al., 2010 \& Paddock, 2006), it is important to ensure that the local community residents and other stakeholders at least communicate and cooperate to ensure the sustainability of tourism-driven MPAs. This brings a few questions to mind: To what extent do the stakeholders interact and cooperate? What are residents' perceptions toward the positive and negative externalities that the diving industry could generate over the hosting destination? Do residents realise that they are stakeholders in MPAs and SDTSs? Do residents partake in the SDTS? By answering these questions, a greater understanding will be created regarding the management of MPAs and SDTS about the people living within such areas, as well as how and to what extent they need to participate in the marine tourism 
industry. Such research will contribute to both literature and practical management.

To answer these questions, the primary aim of this study was to measure and analyse the interactions between the residents and dive operators as key stakeholders of the MPA and SDTS. This was done by inquiring about the interaction and cooperation among stakeholders regarding the stakeholders' understanding of each other, as well as to what extent they communicate with one another. The residents' social impact perception of the scuba diving industry and their level of awareness of their role as stakeholders were also measured in terms of the social exchange theory in order to test to what extent they receive benefits from the industry in the instance that they perhaps do not see themselves as part of the MPA or SDTS. This was done to determine to what extent they support the scuba diving industry as well as to see if they might deter their support if they are not fully incorporated and treated as stakeholders.

\section{Background to the study}

\section{Residents and the dive industry}

Countless studies have demonstrated the importance of residents' goodwill and support for the sustainability of tourism endeavours in view of the fact that they have to share their surroundings, buildings and institutions, transport systems, catering, accommodation and other services with tourists (Godfrey \& Clarke, 2007; Muganda, Sirima \& Ezra, 2013; Scholtz \& Slabbert, 2015). Tosun (2006) and Saayman (2013) argue that community involvement, participation and empowerment have the potential to resolve community issues such as development, planning and management of shared resources. Proper management of the social impacts generated by the tourism industry will also contribute towards residents' goodwill and support. Two models that perhaps best explain how resident perceptions function, are the social exchange theory (SET) and the stakeholder theory. SET states that there should be a mutual exchange among two parties - in tourism terms, residents are more likely to overlook smaller adverse social effects if they derive direct positive impact from tourism activities (Gursoy, Jurowski \& Uysal, 2002; Kuvan \& Akan, 2005).
Stakeholder theory, on the other hand, explains how various stakeholders in the tourism industry should be managed which in this case would help to create a more sustainable SDTS within an MPA (Freeman, 2014). For instance, the residents, dive operators, tourists and all other service providers within the tourism industry are stakeholders who should continually be consulted for an industry to be sustainable. According to Hall and Richards (2006), the mix of stakeholders and their views differs from one community to another - each community needs to be examined, understood and managed as a unique entity, as it has its own political and institutional culture(s) affecting the destination. Differing views, in turn, can influence the participation of stakeholders in the tourism planning process.

It is clear from the literature that residents need to derive benefits from the tourism industry and that they have to be treated as stakeholders for them to perceive benefits.

\section{Gaining residents' support}

One of the main aspects that influence residents' support for the tourism industry is the perceived positive and negative social impacts generated by it (Deery, Jago \& Fredline, 2012). Positive impacts can include job creation, improved economy, improved community image, development of infrastructure or improved surroundings (Gursoy et al., 2002; Kuvan \& Akan, 2005; Mowforth \& Munt, 2016; Saayman, 2013; Williams \& Lawson, 2001). On the other hand, negative social impacts can include a rise in crime levels, degradation of the environment, congestion and xenophobia (Mowforth \& Munt, 2016; Raj \& Musgrave, 2009). If the negative social impacts become too prevalent, resident support for the tourism industry might weaken and eventually turn into negative feelings, or even aggression, towards visitors. Therefore, it is critical that the social impacts be appropriately managed to minimise the negative impacts and maximise the positive (Kreag, 2007).

\section{Resident participation}

According to Saayman (2013), to ensure successful tourism planning, it is essential to involve the residents and motivate them to participate, as it will help lessen the negative 
social impacts generated by the industry and, at the same time, promote the positive impacts (Deery et al., 2012). A study by Tosun (2000) found that when residents are made part of the tourism industry through a participatory development approach, it enables better opportunities for residents to obtain more balanced benefits from tourism developments in their community. This, according to Inskeep (1994), will foster positive resident sentiment towards tourism activities, lead to the conservation of local resources, and create visitor satisfaction as well as continued benefits for the residents (Simmons, 1994).

To better understand the forms of resident participation in the tourism management system, Pretty (1995) developed the typology of participation that states that there are various forms of resident involvement such as passive participation by consultation, bought participation, functional participation, interactive participation and self-mobilisation and connectedness. According to the typology, the least participative level of community participation is passive participation by consultation, where total control concerning developments in the community comes from outside forces, whereas on the other end of the typology one finds self-mobilisation and connectedness, where the residents are in complete control. However, according to Mason (2005), the following barriers can hinder residents' participation in tourism planning:

- Residents might find planning and legislation issues confusing and complicated.

- Residents might not understand the process and how decisions are made.

- It might be difficult to get a representative view of a particular problem.

- Residents might simply not care.

- It might cost more regarding money, time and staff.

- It might take longer to make decisions.

Saayman (2013:169) argues that only the communities themselves can 'break existing patterns of power and unequal development', meaning that communities should actively participate in the tourism industry. On the other hand, Jackson (2006) proposes nine steps for 108 the improvement of community participation: The first step includes the identification of the key stakeholders, which might include the residents, business owners, developers and conservation groups, for instance. The second and most important step is to establish communication links amongst stakeholders and to build trust. Stakeholders should share power and have an equal say in tourism development processes. The third step involves the establishment of a collaborative working group that will represent an equal representation of all stakeholders. The fourth step is to determine goals and objectives that will allow for a sustainable balance between socio-economic and ecological sustainability. In the fifth step, experts should be appointed to deal with economic, social and environmental impact studies, after which the area's carrying capacity should be determined in the sixth step so that stakeholders will be aware of how much development can take place before they become negative. In the seventh step, a development plan should be established and approved, while a code of conduct should be developed to guide future developments. Lastly, the plan must be implemented, monitored and controlled. This plan, however, will only work when residents participate in the tourism industry (Mowforth \& Munt, 2016).

\section{The case study area}

The $3.74 \mathrm{~km}^{2}$ Portofino MPA was established in 1999 and covers various small port communities in the Ligurian coast in Genoa province Italy (see Figure 1). Its main purpose is to protect the unique and highly popular marine and terrestrial environment from an ever-increasing number of tourists (Moschella et al., 2005). One of the most essential tourism activities, the scuba diving industry, has been active in the area for approximately half a century, meaning that it is an established STDS with around 20 commercial charter businesses (Area Marina Protetta Portofino, 2016). The expanding marine tourism industry has increased the ecological impacts on the area, prompting the establishment of the Portofino Marine Protected Area (MPA) which is a $13 \mathrm{~km}$ coastline which includes the Portofino Regional Park (Mmmpa.eu, 2017). The Park is managed by various authorities, including the said municipalities, together with the University of 
Genoa and the Metropolitan City of Genoa (Lucrezi et al., 2017).

The MPA has placed restrictions on the consumptive and non-consumptive use of the marine environment, which limit fishing and scuba diving (Moschella et al., 2005). This meant that many residents had to leave the fishing industry and find alternative forms of income. The diving activities are limited to 21 dive sites, with no more than 24 divers allowed at one location simultaneously. In 2001, approximately 60000 dives were reported. However, by 2014, this number had drastically declined to 28000 (Lucrezi et al., 2017).

Dive associations were positive about the imminent introduction of the MPA, as the MPA promised environmental protection as well as economic benefits for the area. However, poor participation and consensus by key stakeholders resulted in an MPA and accompanying STDS in which not all stakeholders were included in planning and implementation (Markantonatou et al., 2016). Because the scuba diving industry (Markantonatou, Noguera-Méndez \& SemitielGarcía, 2016) and residents (Hritz \& Ross, 2010; Moschella et al., 2005; Scholtz \& Slabbert, 2017) were not adequately consulted priorly, it led to antagonistic sentiments from the residents (Markantonatou et al., 2016). Salmona and Verardi (2001) add that there is a significant gap in the stakeholders' perceptions of the tourism operators and related tourism activities (such as scuba diving) on the one hand and employment in other activities on the other hand. The MPA is opposed by 'yachting associations, boating operators, local municipalities, tourist operators and tradesmen', whereas it is mostly supported by scientists, environmental associations and a few tradesmen (Moschella et al., 2005, p. 147).

According to Salmona and Verardi (2001, p. $44)$, this area has always preserved its identity

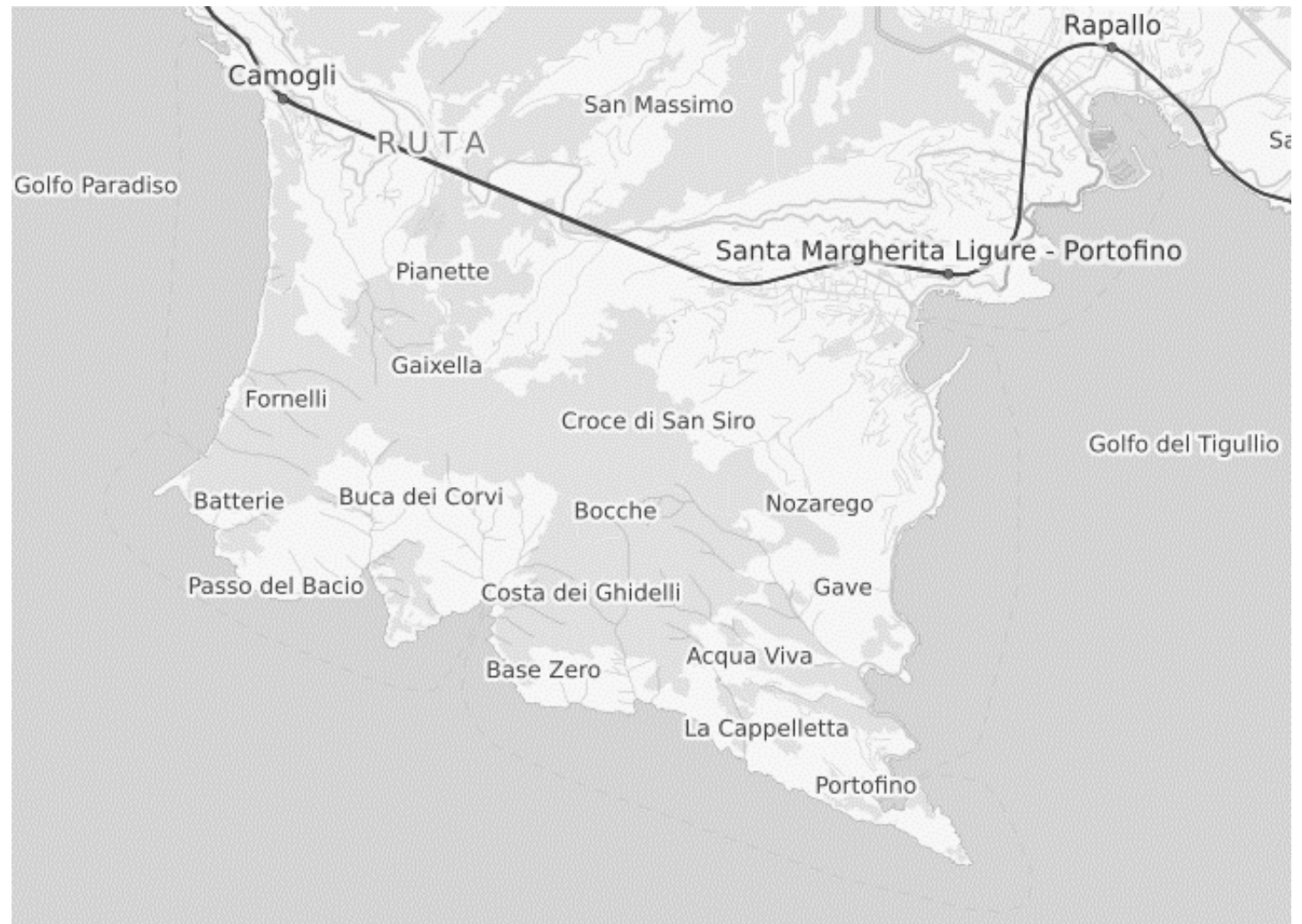

Figure 1: The Portofino MPA study area in Italy (Source: OpenStreetMap.org - open source maps) 
but now has to deal with a 'very rigid economic system'. Residents acknowledge the importance of the ecosystem for their livelihoods, but, paradoxically, do not want the tourism industry to be regulated. Due to a lack of innovation, there is also a severe shortage of job opportunities, as residents mostly cater solely to the elite (high income) tourists. Also, most tourism operator head offices are located outside the area in which they operate, meaning that residents do not form part of such operations' planning and management. This has led to a decrease in resident numbers in Liguria (Salmona \& Verardi, 2001).

A study by Lucrezi et al. (2017, p. 385) has examined the SDTS and its sustainability in terms of interactions between the scuba divining industry and the 'environment, economy, non-monetary aspects, society, governance, and scientific community' by interviewing dive operators in the Portofino MPA as well as in Ponta do Ouro in Mozambique. It was found that operators perceived scuba diving as vital to them, the MPA and the residents, yet perceived little support from the broader tourism industry and residents. Thus, cooperation and participation from stakeholders such as the residents are lacking and problematic. Summarised (Moschella et al., 2005), the success of the PMPA and STDS is currently limited by 1) poor social participation (only a few influential economic sectors are involved); 2) ignorance regarding public environmental awareness; 3) lack of coordination by the PMPA and other management parties; and 4) poor enforcement of the PMPA laws (Salmona \& Verardi, 2001). Salmona and Verardi argue that the PMPA will be successful when the public acknowledges the long-term economic and ecological benefits that will stem from a proper management plan for the environment. As of yet, the communication from the PMPA remains ineffective or absent; it is, therefore, important that the other stakeholders in the industry are engaged to ensure that they (at least) communicate and cooperate.

\section{Research method}

This study followed a mixed-method approach using a sequential exploratory design (Creswell $\&$ Clark, 2011). The first part was qualitative, whereas the second was quantitative. This was done to obtain an understanding of the perception of the dive operators within the industry and their views regarding the community (through interviews). The dive operators' perceptions, in turn, helped with the development of the questionnaire to determine and corroborate or contrast the communities' views of the scuba diving industry, as well as the social impacts generated by the industry (through questionnaires).

\section{Semi-structured interviews with dive operators}

Firstly, a qualitative method of data collection was used to collect information from dive operators using semi-structured, face-to-face interviews with the assistance of an interpreter. This sample consisted of eight dive operators and one dive instructor who were interviewed in August 2015. These eight individuals were the ones who agreed to the interviews out of a possible ten who operated in the region. Two of the dive operators worked together at one establishment and provided a combined view. Two respondents were from the Municipality of Rapallo, one from Camogli and five from Santa Margherita Ligure. The dive operators were contacted beforehand to schedule the interviews at their dive centres.

Before starting the interviews, the researcher explained the purpose of the study and asked permission to audio record the interviews. The interviews were guided by a semi-structured questionnaire that allowed for follow-up questions. Each interview lasted between 45 minutes and an hour. The purpose of this questionnaire was to determine, using six central questions, the dive operators' opinions regarding their perceptions of the residents towards the scuba diving industry and to determine the state of communication between them (the industry) and the residents. The operators were asked to 1) describe their perceptions of residents' awareness and understanding of the scuba diving industry and MPA; 2) explain to what extent residents are involved in and participate in the scuba diving industry; 3) rate and explain the current level of communication and cooperation among stakeholders, as well as their opinions about what should be done to improve the situation; 4) share their thoughts on the importance of 
residents' support for the tourism industry; and 5) indicate whether residents experience positive and negative social impacts from the tourism industry and whether they value the industry. An information saturation method was employed to ensure that the researchers fully understand the dive operators' perceptions. This was done through detail-orientated, elaboration and clarification probes, to ensure that the maximum volume of data would be obtained (Maree, 2016). In the results and discussion, each dive operator was codenamed as operator 1 to operator 8 .

\section{Resident questionnaire survey}

The second phase of the research followed a quantitative, non-experimental, descriptive technique of data collection using a structured questionnaire that was distributed to residents of particular municipalities with active scubadiving activities in the Portofino MPA (discussed in later in this section). This survey was done to determine the different or similar perceptions of the residents towards the dive operators and the scuba diving industry in general, as well as to measure the residents' social impact perceptions of the scuba diving industry. The questionnaire comprised four sections: The first section captured sociodemographic data such as age, length of stay in the community, level of education and whether the residents work in the tourism industry, whereas the second section, using semantic scales, measured residents' perceptions concerning tourism and the scuba diving industry's influence on their personal lives, as well as the influence on the community as a whole. The third section measured residents' social impact perceptions (about 35 social impact statements) on a five-point Likert scale on which ' 1 ' indicated strongly disagree and ' 5 ' indicated fully agree. The statements were obtained from various social impact studies (Higgens-Desboilles, 2006; Scholtz \& Slabbert, 2015; Slabbert \& Viviers, 2013). Finally, Section D measured residents' perceptions of the current state of the scuba diving industry in their community and the aspects that contributed towards that current state. It was done on a five-point Likert scale with the same scales used as in Section C. This Likert scale consisted of 28 statements that were synthesised and adjusted from literature with findings on the Portofino MPA (Moschella et al., 2005; Salmona \& Verardi, 2001), studies on resident participation (Tosun, 2000), studies on social impact perceptions (Scholtz \& Slabbert, 2015), as well as the themes and subthemes obtained from the interviews.

The questionnaires were distributed through convenience sampling, as it was impossible to apply probability sampling with the high number of residents who declined to participate. Fieldworkers made use of the survey intercept method where they approached people in shops and on the streets where the screening question "Are you a resident of this area?" was asked before proceeding. Residents from Santa Margherita Ligure (48\%), Rapallo (26\%), Camogli (18\%) and other smaller communities $(8 \%)$ formed part of the sample.

The questionnaires were distributed during two surveys, the first in August/September 2015, when 68 (n) completed questionnaires were collected over 25 days and the second in August 2016, when only completed 38 (n) additional questionnaires were obtained over 24 days. To avoid duplication, the researchers made a list of shops, hotels and areas where the questionnaires were distributed during the first survey. The two samples were pooled together to achieve a small, yet usable sample of $106(n)$. The approximate population size of $45800(\mathrm{~N})$ included Santa Margherita Ligure (n $=9639)$, Rapallo $(n=30742)$ and Camogli $(n$ $=5455)$.

The 106 collected questionnaires provide a $95 \%$ confidence level with a $9.5 \%$ margin of error (5\% error or lower is preferred). The majority of the over 600 people who were intercepted and asked to participate in the survey declined, or indicated that they were not residents of the area, but instead stayed in other peoples' holiday homes - therefore a smaller than expected sample.

\section{Data analysis}

The recordings from the semi-structured interviews were transcribed and divided into five themes, defined a priori (Maree, 2016) according to the questions asked that emerged from literature. Subthemes arose from the six 
main themes and were also discussed. The questionnaire data were captured in Microsoft Excel and analysed in IBM SPSS Statistics 23. Through descriptive statistics, the profiles of residents, as well as their awareness, knowledge and perceptions of the scuba diving industry, were compiled. The results and statements used in this study were based on the themes and subthemes identified in the dive operator interviews. Also, a comparison was made between the descriptive statistics of the social impacts and scuba diving industry perceptions and the themes discovered from the analysis of the interviews to point out similarities and gaps in communication. Lastly, a comparison was made between the perception of the residents who scuba dive and those who do not, as well as those who are aware of the existence of the scuba diving industry, and those who were not. The latter analyses were done using t-tests. To ease reading, the researchers furthermore refer to dive operator respondents as 'operators' and resident respondents as 'residents'.

\section{Results}

Results of the dive operator interviews

Most operators were Italian men in their late 40s with high school qualifications and approximately 17 years of experience in the industry. They were the owners, co-owners or CEOs of the respective dive companies in which they had been working for eight years on average (Table 1).

From the interviews, five main themes were identified that were similar to the questions asked, namely Awareness and perceptions of MPA and scuba diving; Residents' involvement and participation; Communication and cooperation among stakeholders; Residents support for the tourism industry; and Perceptions regarding the social impacts of the scuba diving industry. Under each theme, various subthemes were identified. Analysis of operator responses according to the themes will now be discussed.

Theme 1: Awareness and perceptions of MPA and scuba diving

Operator 1 argued that the residents 'do not even know that they live in an MPA or that there is a Park [adjacent to their community]', to which the majority agreed. Operator 4 added that residents perceive the sea as a place for 'bathing and fishing', instead of diving. Operator 4 continued by stating 'local institutions are becoming characterised by younger people' and that younger people 'are beginning to understand the needs of people coming to [the] seaside resorts', but it is difficult seeing as they live 'in centre of area where it is a fishing industry' as perceived by 'older people'.

Theme 2: Residents' involvement and participation

Operator 5 strongly argues that "not many people in this area is involved in scuba diving' and that it is partly to blame due to the MPA that "promotes itself elsewhere, but not at local level such as schools". Most scuba divers agreed that residents are not involved in the industry, but that divers rather come from other larger cities or '...from outside [other countries]' (Operator 8). However, Operators 5 and 8 stated that the community found Santa Margherita Ligure to be 'expensive' and 'overpriced' to take part in the industry. Another operator (Operator 6) suggested that 'residents

Table 1. The dive operator profile

\begin{tabular}{ll}
\hline Aspects & Dive operators \\
\hline Nationality & $6-$ Italian; 1 - Peruvian; 1 - Cuban \\
Average age & 47 years (average) \\
Gender & $7-$ male; 1 - female \\
Education & $1-$ PhD; 1 - Degree; $6-$ High school \\
Marital status & $1-$ Married; $1-$ Divorced; $2-$ Living together; $4-$ \\
& Unknown \\
Status in business & CEO/Owner/Co-owner \\
Years in industry & $11-20($ Average $=16.5)$ \\
Years at current operation & $1-17$ (Average $=8.3)$ \\
\hline
\end{tabular}


cater for scuba divers, but do not know that they do sport', meaning that the residents form part of the scuba diving industry, but are not even aware.

Theme 3: Communication and cooperation among stakeholders

Operators communicate mostly with residents who work in the tourism industry and avoid other residents actively as '...community sees divers as nuisance' (Operator 3). Operator 5 reports '...hostility from the community' in that they get "dirty looks" from residents when heading out with tourists. Operator 3 continues by stating that operators '...manage to survive here due to their location' by for instance opening their business '...on [the] other side of the street...' to avoid residents who live closer to the beach. Operator 4 adds that 'Restaurants and businesses are starting to look after us and give us importance. Hospitality sector is more collaborative'. Operator 7 also experienced '...small collaboration with the hospitality sector.' These views are, however, not shared by Operators 1 and 5 who claim that hotels, for instance, '...prefer to stay closed during the winter. However, scuba divers dive all seasons' (Operator 1). Most operators argued that the area's accommodation quality is low and the prices are high. They attributed the latter situation to the fact that 'Ligurian people have an old mentality' (Operator 4). Operators find it difficult to find accommodation for their clients during the low season because scuba diving is a year-round activity in the area. They reported that the local tourism industry does not like scuba divers and that communication and cooperation remains a major problem. The operators suggested that it is the MPA's responsibility to facilitate communication among stakeholders and that the MPA should rather promote itself at a local level instead of elsewhere (provincially, nationally and international). One Operator 6 suggested that dive operators can build a better relationship with the residents by 'respecting local practices [and] try[ing] to fit in'.

Theme 4: Residents' support for the tourism industry

It was clear from the interviews that operators perceive resident support as '...very important...' (Operator 6) for the sustainability of the industry. However, dive operators feel unwelcome and experience some hostility from the residents, making it difficult to conduct their business. The residents will give "dirty looks" (Operator 5), make derogatory remarks and even refuse service to scuba divers, in some instances. Furthermore, the operators feel that the industry will not survive if the residents do not support them.

Theme 5: Perceptions regarding the social impacts of the scuba diving industry

When examining operators' perceptions of the social impacts generated by the scuba diving industry a few impacts or aspects were named. Operators feel that residents see divers as messy, noisy, dirty, and an overall nuisance. As a result, operators attempt to avoid the residents are far as possible. They will, for instance, rather not have their shops next to the beach, but further in town. Operators feel that residents also prefer scuba divers not to walk on the Esplanade, as they look 'ugly' and 'semi-naked divers do not look good' (Operator 8). Furthermore, operators feel that residents do not perceive or acknowledge the positive impacts generated by the scuba diving industry, regardless of whether residents work in the tourism industry or not. Operator 8 adds that 'If they don't dive, I don't see how they can appreciate'. Operator 2 argued that residents are thought to be unfriendly and rude to tourists in general, which operators fear will give the community a poor image. Regardless, Operator 7 exclaimed that 'statistics clearly show that scuba diving boosts the area's tourism and income; the MPA is dependent on tourism'.

\section{Results of the resident questionnaire \\ Profile of residents}

Respondents had an average age of 41 years; $78 \%$ were permanent residents, and $22 \%$ stayed in the sample municipalities for specific periods of the year (see Table 2). On average, they had been part of their respective communities for 25 years and $82 \%$ at the time of the survey worked in the tourism industry (hospitality, restaurants/bars, travel agents or transport). The majority had obtained at least a high school diploma or equivalent. Although $98 \%$ were aware of the MPA and $80 \%$ of scuba diving activities in the area, only $52 \%$ indicated 
that they know what scuba diving is. Furthermore, only $16 \%$ were scuba divers, whereas $32 \%$ believed that their jobs/businesses form part of the scuba diving industry. When asked about the impact of tourism on their community quality of life, respondents felt that tourism was positive to very positive $(75 \%)$. When measuring the effect of tourism on the community as a whole, respondents indicate also indicate a positive to very positive effect (88\%), but to a larger extent. On the other hand, when measuring the impact of scuba diving on their personal lives, they felt that it had no effect $(55 \%)$, or a slightly positive effect, while the effect on the community as a whole was seen as slightly positive to very positive (83\%). They do, however, acknowledge that scuba diving contributes positively to very positively to their communities. Lastly, respondents indicated that they do enjoy living in their communities, but that they would not mind moving somewhere else $(61 \%)$.
Residents' social impact and scuba diving industry's perceptions according to themes

Towards a better understanding of cooperation and participation between residents and the scuba diving industry, the researcher used the themes and subthemes identified from the interviews with the dive operators to categorise the residents' social impact and scuba diving perceptions accordingly. Only statements applicable to the themes and subthemes were manually extracted to obtain the residents' similar or opposing opinions. The categorisation is displayed in Table 3 . Some statements might be repeated, as they fit within more than one theme/sub-theme. The statements are discussed in Section 5.

Differences in resident perceptions about divers and scuba diving awareness

The t-test revealed four significant differences between the two groups regarding those who scuba dive and those who do not (Table 4). Those who do scuba dive feel that scuba diving has a more positive influence on their personal

Table 2. The resident profile

\begin{tabular}{|c|c|}
\hline \multicolumn{2}{|l|}{ Socio-demographic information } \\
\hline Age & 40.52 years (average) \\
\hline Permanent resident & Yes $(78 \%)$ \\
\hline Communities that respondents are residents of & Santa Margherita Ligure (30\%), Rapallo (21\%) \\
\hline Years as resident & 25.48 years \\
\hline Business as part of tourism & Yes $(82 \%)$ \\
\hline Type of business & $\begin{array}{l}\text { Hospitality }(34 \%) \text {, restaurant/bar (17\%), travel agent/transport } \\
(17 \%)\end{array}$ \\
\hline Level of education & High school diploma or equivalent $(60 \%)$ \\
\hline \multicolumn{2}{|l|}{ Scuba diving knowledge } \\
\hline Do respondents know what scuba diving is? & Yes $(52 \%)$ \\
\hline Aware of scuba diving in the area? & Yes (80\%) \\
\hline Aware of MPA? & Yes $(98 \%)$ \\
\hline Respondent as scuba diver & No $(84 \%)$ \\
\hline Business involvement in scuba diving industry & No $(68 \%)$ \\
\hline \multicolumn{2}{|l|}{ Effect of tourism and scuba diving } \\
\hline Effect of tourism on personal quality of life & $\begin{array}{l}\text { Positive to very positive (75\%), No effect (3\%), Very negative } \\
(3 \%)\end{array}$ \\
\hline Effect of tourism on community quality of life & $\begin{array}{l}\text { Positive to very positive ( } 88 \%) \text {, Slightly positive }(7 \%) \text {, No } \\
\text { effect }(2 \%) \text {, Slightly to very negative }(3 \%)\end{array}$ \\
\hline Effect of scuba diving on personal quality of life & $\begin{array}{l}\text { No effect }(55 \%) \text {, Slightly positive ( } 28 \%) \text {, Positive to very } \\
\text { positive }(14 \%) \text {, Slightly to very negative }(3 \%)\end{array}$ \\
\hline $\begin{array}{l}\text { Effect of scuba diving on community quality of } \\
\text { life }\end{array}$ & $\begin{array}{l}\text { Slightly positive to positive }(72 \%) \text {, Very positive (11\%), No } \\
\text { effect }(13 \%) \text {, Slightly to very negative }(3 \%)\end{array}$ \\
\hline Community attachment & $\begin{array}{l}\text { I enjoy living in my community, but I can think of other places I } \\
\text { would equally enjoy staying in }(61 \%) \text {, I stay here only } \\
\text { because circumstances do not allow me to leave }(15 \%)\end{array}$ \\
\hline \multicolumn{2}{|c|}{ Perception of current state of tourism industry } \\
\hline Current state of scuba diving industry & Good (43\%); average (40\%); very good (11\%) \\
\hline
\end{tabular}


Table 3. Residents' perceptions of the scuba diving industry

\begin{tabular}{|c|c|c|c|c|c|c|c|c|}
\hline $\begin{array}{l}\text { Social impact and scuba diving industry perceptions categorised, based } \\
\text { on themes and subthemes }\end{array}$ & 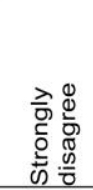 & 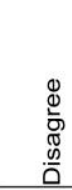 & $\begin{array}{l}\bar{\pi} \\
\stackrel{5}{5} \\
\text { Z }\end{array}$ & 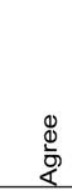 & 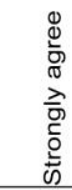 & $\begin{array}{l}\frac{0}{J} \\
\frac{1}{\pi} \\
> \\
\frac{1}{\pi} \\
\sum \\
\Sigma\end{array}$ & SE & 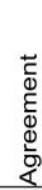 \\
\hline \multicolumn{9}{|l|}{ Awareness and understanding of MPA and scuba diving } \\
\hline I have become more knowledgeable about marine life. & $8 \%$ & $12 \%$ & $43 \%$ & $31 \%$ & $6 \%$ & 3.14 & 0.100 & + \\
\hline My community has become more environmentally friendly. & $8 \%$ & $4 \%$ & $30 \%$ & $38 \%$ & $19 \%$ & 3.57 & 0.110 & ++ \\
\hline I have developed a greater appreciation for the marine environment. & $1 \%$ & $6 \%$ & $34 \%$ & $42 \%$ & $16 \%$ & 3.67 & 0.086 & ++ \\
\hline I have developed respect for the tourism industry. & $3 \%$ & $9 \%$ & $52 \%$ & $32 \%$ & $4 \%$ & 3.24 & 0.081 & + \\
\hline I have developed respect and understanding for visitors. & $16 \%$ & $35 \%$ & $35 \%$ & $12 \%$ & $2 \%$ & 2.49 & 0.099 & -- \\
\hline I get to learn more about other visiting cultures. & $9 \%$ & $17 \%$ & $41 \%$ & $31 \%$ & $2 \%$ & 2.99 & 0.100 & M \\
\hline \multicolumn{9}{|l|}{ Residents' involvement and participation } \\
\hline The participation levels of residents in this industry & $7 \%$ & $21 \%$ & $50 \%$ & $16 \%$ & $6 \%$ & 2.93 & 0.097 & - \\
\hline \multicolumn{9}{|l|}{ Communication and cooperation among stakeholders } \\
\hline The offering of value for money experiences & $3 \%$ & $9 \%$ & $44 \%$ & $37 \%$ & $6 \%$ & 3.34 & 0.087 & + \\
\hline Fair prices being charged & $2 \%$ & $10 \%$ & $60 \%$ & $27 \%$ & $1 \%$ & 3.15 & 0.072 & + \\
\hline The area offering good accommodation facilities & $3 \%$ & $9 \%$ & $37 \%$ & $43 \%$ & $7 \%$ & 3.42 & 0.089 & + \\
\hline $\begin{array}{l}\text { The good understanding between community members and the scuba } \\
\text { diving industry }\end{array}$ & $7 \%$ & $10 \%$ & $55 \%$ & $26 \%$ & $2 \%$ & 3.06 & 0.086 & + \\
\hline $\begin{array}{l}\text { Cooperation among community members and those working in the } \\
\text { scuba diving industry }\end{array}$ & $4 \%$ & $11 \%$ & $53 \%$ & $30 \%$ & $1 \%$ & 3.13 & 0.080 & + \\
\hline An efficient flow of information among all stakeholders & $7 \%$ & $16 \%$ & $45 \%$ & $29 \%$ & $3 \%$ & 3.05 & 0.095 & + \\
\hline $\begin{array}{l}\text { There are more opportunities for residents to partake in tourism } \\
\text { planning. }\end{array}$ & $14 \%$ & $30 \%$ & $32 \%$ & $18 \%$ & $6 \%$ & 2.73 & 0.112 & - \\
\hline \multicolumn{9}{|l|}{ Residents' support for the tourism industry } \\
\hline Residents understanding the value of the scuba diving industry & $7 \%$ & $11 \%$ & $40 \%$ & $37 \%$ & $4 \%$ & 3.20 & 0.097 & + \\
\hline Residents understanding the importance of the scuba diving industry & $7 \%$ & $10 \%$ & $50 \%$ & $32 \%$ & $1 \%$ & 3.11 & 0.102 & + \\
\hline The participation levels of residents in this industry & $7 \%$ & $21 \%$ & $50 \%$ & $16 \%$ & $6 \%$ & 2.93 & 0.097 & M \\
\hline $\begin{array}{l}\text { Residents' general positive attitude towards the local scuba diving } \\
\text { industry }\end{array}$ & $8 \%$ & $19 \%$ & $47 \%$ & $24 \%$ & $2 \%$ & 2.93 & 0.094 & 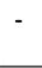 \\
\hline
\end{tabular}

\section{Perceptions regarding the impacts of the scuba diving industry Negative impacts}

The lives of residents are disrupted.

My environment is noisier.

There are, at times, too many visitors in the area.

Businesses are only doing well at certain times of the year.

There are more traffic problems. Positive impacts

There are more opportunities to run local businesses.

I have developed respect and understanding for visitors.

More job opportunities are created in my community.

Residents earn more money.

A sense of greater value is felt in my community.

My community has developed a positive image.

New infrastructure is developed.

The local cultures are protected.

\begin{tabular}{lllllllll}
$1 \%$ & $6 \%$ & $38 \%$ & $38 \%$ & $17 \%$ & 3.64 & 0.09 & ++ \\
$3 \%$ & $3 \%$ & $30 \%$ & $52 \%$ & $12 \%$ & 3.67 & 0.09 & ++ \\
$11 \%$ & $30 \%$ & $33 \%$ & $18 \%$ & $7 \%$ & 2.80 & 0.11 & - \\
$3 \%$ & $8 \%$ & $43 \%$ & $40 \%$ & $6 \%$ & 3.38 & 0.09 & + \\
$15 \%$ & $38 \%$ & $28 \%$ & $12 \%$ & $7 \%$ & 2.58 & 0.11 & - \\
& & & & & & & \\
$1 \%$ & $4 \%$ & $24 \%$ & $50 \%$ & $20 \%$ & 3.85 & 0.084 & ++ \\
$16 \%$ & $35 \%$ & $35 \%$ & $12 \%$ & $2 \%$ & 2.49 & 0.099 & - \\
$2 \%$ & $10 \%$ & $38 \%$ & $42 \%$ & $8 \%$ & 3.44 & 0.089 & + \\
$9 \%$ & $18 \%$ & $40 \%$ & $30 \%$ & $3 \%$ & 3.01 & 0.097 & + \\
$2 \%$ & $11 \%$ & $38 \%$ & $36 \%$ & $13 \%$ & 3.47 & 0.094 & + \\
$6 \%$ & $7 \%$ & $30 \%$ & $49 \%$ & $8 \%$ & 3.46 & 0.096 & + \\
$2 \%$ & $16 \%$ & $34 \%$ & $39 \%$ & $8 \%$ & 3.35 & 0.094 & + \\
$5 \%$ & $5 \%$ & $46 \%$ & $37 \%$ & $7 \%$ & 3.36 & 0.088 & + \\
\hline
\end{tabular}

Note: a '+' signifies a Slight trend towards agreement, while a '++' signifies a strong trend towards agreement and an 'M' - mixed responses. On the other hand, a '-' means that respondents slightly disagree and '--' that they strongly disagree.

life $(M=5.79, S D=1.188)$ than those who do not. Pertaining to the social impact statements, those who do scuba dive perceived a significantly larger improvement in their daily lifestyle $(M=3.43, S D=0.756)$, and also a sense of greater value in their community $(M=4.42$, $S D=1.051$ ), while rating the degradation of the community's surroundings significantly lower $(M=1.71, S D=0.825)$ than those who do not scuba dive.
Furthermore, the differences in respondent perceptions regarding their awareness of the scuba diving industry were also measured. It was found that those who are aware of the scuba diving industry perceived tourism as having a more positive impact on their personal lives $(M=6.22, S D=0.847)$ (measured on a 7point semantic differential scale). Also, when examining their perceptions of the social impacts generated by tourism, they felt more proud to be associated with their community 
Table 4. Differences in resident perceptions

\begin{tabular}{|c|c|c|c|c|}
\hline Aspects & $\begin{array}{l}\text { Do scuba dive } \\
(n=14) \\
\text { Mean and standard } \\
\text { deviation }\end{array}$ & $\begin{array}{l}\text { Do not scuba dive } \\
(n=72) \\
\text { Mean and standard } \\
\text { deviation }\end{array}$ & t-values & p-value \\
\hline $\begin{array}{l}\text { Influence of scuba diving on personal } \\
\text { life }\end{array}$ & $5.79( \pm 1.188)$ & $4.21( \pm 0.868)$ & 5.609 & 0.000 \\
\hline my everyday lifestyle has improved & $3.43( \pm 0.756)$ & $2.73( \pm 0.687)$ & 3.395 & 0.005 \\
\hline $\begin{array}{l}\text { my community's natural surroundings is } \\
\text { degrading }\end{array}$ & $1.71( \pm 0.825)$ & $2.42( \pm 0.962)$ & -2.566 & 0.012 \\
\hline $\begin{array}{l}\text { A sense of greater value is felt in my } \\
\text { community }\end{array}$ & $4.42( \pm 1.051)$ & $3.37( \pm 0.913)$ & 3.080 & 0.003 \\
\hline Aspects & $\begin{array}{l}\text { Aware of scuba } \\
\text { diving in } \\
\text { community } \\
\text { ( } n=81 \text { ) } \\
\text { Mean and standard } \\
\text { deviation }\end{array}$ & $\begin{array}{l}\text { Not aware of scuba } \\
\text { diving in } \\
\text { community } \\
(n=20) \\
\text { Mean and standard } \\
\text { deviation }\end{array}$ & t-value & p-value \\
\hline Tourism impact on personal life & $6.22( \pm 0.847)$ & $5.11( \pm 0.847)$ & 3.731 & 0.000 \\
\hline $\begin{array}{l}\text { I feel proud to be associated with my } \\
\text { community }\end{array}$ & $3.42( \pm 0.860)$ & $2.90( \pm 1.071)$ & 2.268 & 0.026 \\
\hline $\begin{array}{l}\text { my community has developed a positive } \\
\text { image }\end{array}$ & $3.53( \pm 0.901)$ & $3.10( \pm 1.071)$ & 1.808 & 0.074 \\
\hline new infrastructure is developed & $3.44( \pm 0.882)$ & $2.90( \pm 0.968)$ & 2.369 & 0.020 \\
\hline $\begin{array}{l}\text { more job opportunities are created in } \\
\text { my community }\end{array}$ & $3.53( \pm 0.801)$ & $3.05( \pm 0.970)$ & 2.233 & 0.028 \\
\hline the local cultures are protected & $3.46( \pm 0.774)$ & $2.85( \pm 1.089)$ & 2.868 & 0.005 \\
\hline the lives of residents are disrupted & $3.75( \pm 0.887)$ & $3.26( \pm 0.806)$ & 2.160 & 0.033 \\
\hline $\begin{array}{l}\text { I have developed a greater appreciation } \\
\text { for the marine environment }\end{array}$ & $3.77( \pm 0.863)$ & $3.20( \pm 0.768)$ & 2.697 & 0.008 \\
\hline $\begin{array}{l}\text { A sense of greater value is felt in my } \\
\text { community }\end{array}$ & $3.59( \pm 0.902)$ & $3.00( \pm 0.973)$ & 2.542 & 0.013 \\
\hline
\end{tabular}

$(\mathrm{M}=3.42, \mathrm{SD}=0.860)$, perceived a more positive community image $(\mathrm{M}=3.53, \quad \mathrm{SD}=0.901)$, observed more infrastructure developments $(\mathrm{M}=3.44, \mathrm{SD}=0.882)$, more job opportunities $(\mathrm{M}=3.53, \mathrm{SD}=0.801)$, that local cultures are better protected $(M=3.46, S D=0.774)$, they developed a greater appreciation for the marine environment $\quad(M=3.77, \quad S D=0.863), \quad$ and experienced a greater sense of value in their community $(M=3.59, \quad S D=0.902)$. However, they did suffer a greater level of disruption to the lives of the residents because of the scuba diving industry $(\mathrm{M}=3.75, \mathrm{SD}=0.887)$.

\section{Discussion}

The following section contains the comparative results of the dive operators and residents.

\section{Awareness and perceptions of MPA and scuba diving}

The operators were of the opinion that residents are not aware of the MPAs existence and that residents 'do not even know that they live in an MPA or that there is a park' adjacent to their communities, whereas the hospitality industry is perceived as more aware of these facts. Residents are believed to possess the mindset that the sea is only for "bathing and fishing'. One operator explained that younger people who are beginning to work in local institutions are more understanding of the importance of marine tourism activities such as scuba diving, whereas older people believe that the community's economy should rely on fishing operations. Some operators attempted to educate the local children about scuba diving at schools but reported that the children were apathetic. Contrary to the views of operators, almost all residents (98\%) were aware that they were living in an MPA, with $80 \%$ aware of the presence of diving activities. However, only $52 \%$ of residents indicated that they fully understood what scuba diving is (see Table 2). Residents agreed to strongly agree with the 
following statements about their awareness and understanding of the scuba diving industry: My community has become more environmentally friendly $(\bar{x}=3.57 ; \mathrm{SE}=0.11)$ and I have developed a greater appreciation for the marine environment $(\bar{x}=3.67$; SE $=0.086)$. From this section, it is clear that there may be differences in the perceptions of these two stakeholders towards awareness of the PMPA and its relationship with residents.

\section{Residents' involvement and participation}

The majority of operators (75\%) indicated that residents do not participate in the scuba diving industry or in scuba diving activities, but that their customers instead originate from greater cities such as Genoa and other countries. Two operators indicated that a small number of residents dive with them. Most operators could not provide reasons for the lack of resident participation, although some thought that it might be too expensive for residents. One operator explained that he trained two residents to dive, but that they stopped immediately afterwards due to a lack of funding.

The survey data showing that only $16 \%$ of residents take part in scuba diving activities and that $32 \%$ of resident business owners perceived their businesses as directly involved in the scuba diving industry support the dive operators' perceptions. In contrast, $82 \%$ of residents (see Table 2) indicated that they were working in the tourism industry in businesses such as hospitality (34\%) and restaurants and bars $(17 \%)$, or as travel agents and transport companies (17\%). When examining the aspects that contribute towards the success of the scuba diving industry, the residents indicated that, to an extent, they disagree that the participation levels of the residents $\overline{(}^{\bar{x}}=$ 2.93; $\mathrm{SE}=0.097$ ) contributed towards the current state of the scuba diving industry. This means that residents might not be aware of the size and importance of the scuba diving industry, or even that they might be catering for visitors who take part in it in terms of accommodation and restaurants for example.

\section{Communication and cooperation among} stakeholders
Most communication from the operators' side is with the tourism industry sectors such as hotels and restaurants, but they claim to actively avoid other residents. Some operators feel that the hospitality sector is beginning to collaborate with the operators by assisting them in offering packaged deals. Operators do, however, feel that the low-quality accommodation supplied does not justify the high accommodation costs asked - it is hurting the tourism industry. One operator explains that 'Ligurian people have a strange mentality' in that, previously, 'people from here could place any costs on their services' and that tourists were willing to pay it. However, the cost is currently too high, and it is hurting the tourism industry. He feels that it is due to the older people who live there and have an 'old mentality', whereas younger people who own businesses are more open to change.

From the residents' perspective, they felt that value for money, quality accommodation and experiences contribute positively to the scuba diving industry; they slightly agreed with the statements that the offering of value for money experiences $(\bar{x}=3.34$; SE $=0.087$ ) and fair prices are being charged $(\bar{x}=3.15$; SE $=$ 0.072) are important, but showed more agreement with the statement that the area offers good accommodation facilities ( $\bar{x}=2.42$; $\mathrm{SE}=0.089$ ). When it is low season (after August), hotel owners shut down their hotels rather than lower their prices. Accommodation closures are seen as one of the bigger disadvantages for the scuba diving industry, seeing that scuba diving activities continue throughout the year. As a result, scuba divers have great difficulty in finding accommodation and therefore do not stay long. This is viewed by dive operators as a wasted income opportunity.

Some operators identify poor communication as a significant hurdle and argue that it is the MPA's responsibility (which is managed by the Italian government) to open and manage communication channels among stakeholders. One operator noted that it is paradoxical that the MPA promotes itself elsewhere, but not at local level'. Another operator argued that the local councils do not communicate with other stakeholders in any manner. Only one operator 
claimed to have good communication with the residents - he suggested that when one respects the local practices and space, a mutual relationship will develop among the stakeholders. According to him, residents are more likely to support operators if operators 'try to fit in'.

From the residents' perspective, they agreed to a small extent with statements regarding the contribution of communication among stakeholders as playing a role in a successful scuba diving industry, rating the following statements as neutral: the good understanding between community members and the scuba diving industry $(\bar{x}=3.06 ;$ SE $=0.086)$; cooperation among community members and those working in the scuba diving industry $(\bar{x}=$ 3.13; $\mathrm{SE}=0.08$ ); and an effective flow of information among all stakeholders $(\bar{x}=3.05$; $\mathrm{SE}=0.095)$. Pertaining to the social impact statement, there are more opportunities for residents to partake in tourism planning $\left(^{\bar{x}}=\right.$ 2.73; SE $=0.112$ ), residents, to a small extent, did not agree. From this discussion, the lack of communication and proper cooperation among stakeholders become apparent.

Residents' support for the scuba diving industry The operators believed that the residents' support for the scuba diving industry is vital. Currently, the dive operators feel unwelcome, and it makes it more difficult for them to do business when they do not have the community's support. They argue that the scuba diving industry cannot survive without the support of the other sectors within the community, 'there needs to be a synergy'. Inversely, residents only slightly agree that residents understanding the value of the scuba diving industry $(\bar{x}=3.20$; SE $=0.097)$ and residents understanding the importance of the scuba diving industry $(\bar{x}=3.11$; SE $=0.102)$ contribute to the success of the industry. They furthermore feel that the participation levels of residents in the industry ${ }^{\bar{x}}=2.19$; SE $=0.097$ ) and residents' general positive attitude towards the local scuba diving industry $(\bar{x}=2.93$; SE = 0.094) do not significantly influence the industry's level of success. Therefore, residents do support the industry, but they do not see themselves as part of it.
Perceptions regarding the impacts of the scuba industry

Negative social impact perceptions

Most operators feel that the residents see scuba divers as a 'nuisance' because divers 'don't spend much (money), (they are) messy, (and) dirty'. The operators try to manage the residents' negative perceptions of scuba divers by 'keeping quiet and hiding away from everyone'. To avoid residents, most operators' shops are not located next to the beach. Some operators reported 'hostility from the community', because a scuba diver who is 'walking off the esplanade is ugly, which is true'. When examining residents' perceptions regarding the negative impacts of the scuba diving industry, the residents rated the statements the life of the residents are disrupted $(\bar{x}=3.64$; SE $=0.09)$ and $m y$ environment is noisier $(\bar{x}=3.67$; SE $=0.09)$ as the most significant ones. Furthermore, one operator argued residents who do not take part in the scuba diving industry directly, although working in accommodation or in restaurants, are unfriendly towards tourists. He believed that it gives this destination a poor image, as opposed to places such as 'Tuscany - there is another atmosphere. They are more open'. This is supported by the fact that residents disagreed with the statement I developed respect and understanding for visitors $(\bar{x}=$ 2.49; SE $=0.099$ ). Seasonality has also been mentioned by some operators, as hotels and restaurants would rather close than lower prices. To a small extent, residents agree that businesses are only doing well at certain times of the year $(\bar{x}=3.38$; $\mathrm{SE}=0.09)$ due to the scuba diving industry.

One operator suggested that the scuba diving industry should be regulated by local and national government by creating a 'better definition of the diver at national level and then designating spaces in areas for use for boarding, boats, zoning of activities' as well as the development of designated spaces where operators could fill air tanks in order to reduce noise and costs. It is believed that the latter will decrease the negative social impact perceptions. 
Residents did not perceive any negative environmental or cultural impacts as a result of scuba diving. Also, residents did not perceive other negative impacts such as there is a rise in crime levels $(\bar{x}=1.83 ; \mathrm{SE}=0.11)$ or vandalism has increased in my community $(\bar{x}=$ 2.04; SE = 0.12).

\section{Positive social impact perceptions}

Regardless of the residents' perceptions, most operators do feel that the community receives mostly positive benefits. An operator exclaimed that 'statistics show how scuba (diving) boosts tourism', whereas another operator also noted the revenue that the scuba diving industry generates. The operators argued that the MPA is dependent on tourism, so everyone who works in any form of tourism should at least benefit. Nevertheless, operators are of the opinion that the residents are not necessarily aware of the benefits that they derive from tourism and especially the scuba diving industry.

The latter situation is peculiar, seeing as most of the surveyed residents do value the tourism industry. The majority of residents (75\%) indicated that tourism had a positive to very positive impact on their personal quality of life and, even more so (88\%), on the quality of life in the community as a whole. When asked what the effect of the scuba diving industry was on their personal lives, more than half $(55 \%)$ indicated that it did not have any effect, whereas $46 \%$ perceived it as having a positive to very positive effect on the community as a whole. This means that the residents are aware of the benefits of tourism, but do not experience personal benefits from scuba diving activities. One operator felt that residents would appreciate the industry and its benefits more if residents would also take part in diving activities, whereas another argued that residents do not derive benefits if they do not own or work in restaurants or hotels. Those who are not involved think that there are 'too many tourists'. This, however, was found not to be true. Residents, to an extent, did not perceive that there are, at times, too many visitors in the area $(\bar{x}=2.80$; $\mathrm{SE}=0.11)$ or that there are more traffic problems $(\bar{x}=2.58$; $\mathrm{SE}=$ $0.11)$, for instance. Furthermore, residents also indicated that they perceived the following positive social impacts from tourism: there are more leisure opportunities for residents $(\bar{x}=$ 3.57; SE $=0.086$ ), there are more opportunities to run local businesses $(\bar{x}=3.85$; SE $=0.084$ ), and more job opportunities are created in my community $(\bar{x}=3.44$; SE $=0.089)$.

Residents do, to a small extent, believe that scuba diving has contributed towards the community's image by agreeing with a sense of greater value is felt in my community $(\bar{x}=3.47$; $\mathrm{SE}=0.094)$ and my community has developed a positive image $(\bar{x}=3.46$; SE $=0.096)$. This is also supported by their community attachment, which they rated I enjoy living in my community, but I can think of other places I would equally enjoy staying. Also, they somewhat agreed that new infrastructure is developed $(\bar{x}=3.35$; SE $=0.09)$, local services and infrastructure (such as roads) are maintained $(\bar{x}=3.40 ; \mathrm{SE}=0.091)$ and the local cultures are protected $(\bar{x}=3.36$; SE $=0.088)$.

\section{Findings}

From this study on the scuba diving operators and residents, various findings were made regarding their interactions and cooperation.

The first finding regarding the operators was that they perceived negative sentiments and even hostility from the residents. They also perceive residents as not being knowledgeable on scuba diving's existence and its benefits. Operators indicated that they were unable to let their businesses function optimally due to the residents' lack of cooperation and understanding. The second finding was that residents are well aware of the MPA and its scuba diving industry; they are conscious of the benefits of the tourism and diving industries for the community as a whole, but not on a personal level as corroborated by Scholtz and Slabbert $(2015,2017)$. Most residents work in the tourism industry in accommodation, catering or other forms of service delivery; however, according to the dive operators, they are unaware of the fact that many of their customers could be scuba divers. Furthermore, residents have become more aware of their natural environment and its importance, which 
corroborates the findings of Salmona and Verardi (2001).

The fact that residents acknowledge the importance of the industry for the community as a whole, but not for themselves, was revealed by the third finding. Residents of Liguria do not see themselves as key stakeholders in the Portofino MPA, although dive operators and literature argue that they are (Dimmock \& Musa, 2015; Freeman, 2014; Hritz \& Ross, 2010; Roberts et al., 2001). The residents indicated that their actions and the actions of the industry are independent and will not influence one another. They are of the perception that the scuba diving industry is doing well only because of the ecological beauty and diversity of the area, together with qualified dive operators, but that other stakeholders such as themselves do not play a significant role (Mason, 2015). Markantonatgou et al. (2016) argued that this situation exists because residents were not adequately incorporated into the planning, development or implementation of the MPA while Mason (2015) added argued that residents were just not interested. According to the dive operators, the latter situations are as a result of poor planning and management of the MPA, which according to them, would instead market and communicate the MPA in areas outside the MPA region. This has caused various negative perceptions of the MPA and the STDS. It was also reported by the operators that residents did not want to partake in the initial planning of the MPA. From the residents' side, it was also discovered that they, to a small extent, feel negative towards the scuba diving industry. This is supported by various studies that have revealed the importance of residents' goodwill (Godfrey \& Clarke, 2007; Muganda et al., 2013; Scholtz \& Slabbert, 2015). According to the stakeholder theory, the current state in this MPA is not sustainable, and steps need to be taken for residents to recognise and actively engage in their role as stakeholders (Freeman, 2014).

With the first three findings and the stakeholder theory in mind, it is recommended that the area's tourism offices (government and private associations in charge of managing and promoting tourism in the area) devise a plan to create awareness amongst the various stakeholders, including the MPA, the dive operators and the residents of Liguria, regarding their status, importance and roles as stakeholders. Such communications should be done by using a level of language that is comprehensible to the majority of the population, and planning should be simplified to not discourage residents. Motivating residents to play their part as stakeholders in the SDTS and MPA, according to literature, will increase their support thereof.

The fourth finding was that there is a definite difference in how operators and residents perceive one another. According to Salmona and Verardi (2001), this is due to a lack of communication and understanding among the key stakeholders of the STDS in the Portofino MPA. Seasonality, dynamic weather patterns, the contribution of the scuba diving industry to the residents and the perceptions of the scuba divers' image are where the main differences lie. Improved communication and education among stakeholders might remedy this situation. Residents working in the tourism industry, such as hotel or restaurant owners should meet with the dive operators, together with the representatives of the area's tourism offices and the MPA, to discuss each group's situation and expectations. With excellent communication and understanding, these groups might find a way to develop a plan which will mutually benefit all interested parties.

The fifth finding was that the scuba diving industry has both favorable and adverse effects on the residents (Deery et al., 2012), who feel that their lives are being disrupted and that their environment is noisier as a result of the tourism industry. This might have led to the perceptions of residents being unwelcoming towards scuba divers and dive operators. They also perceive stronger seasonality as a result of the scuba diving industry, which according to the dive operators is unfounded, as the dive industry functions year-round (Mowforth \& Munt, 2016; Raj \& Musgrave, 2009). When examining the positive social effects, it becomes apparent that the residents do not experience positive impact for themselves, even with statistics showing that scuba diving activities contribute economically to the area. 
Instead, residents feel that this industry provides to the community as a whole, as opposed to them personally (Scholtz \& Slabbert, 2015). They acknowledged that there are more leisure opportunities for themselves, as well as opportunities to run local businesses and create more job opportunities. Residents did develop a greater sense of value in their communities and felt more positive regarding the community's image. They also recognised aspects such as improved infrastructure, better maintenance of services and infrastructure, as well the safeguard of their culture (Gursoy et al., 2002; Kuvan \& Akan, 2005; Mowforth \& Munt, 2016; Saayman, 2012; Williams \& Lawson, 2001).

It is recommended that emphasis be placed on educating the community on the importance of the scuba diving industry. MPA and tourism office representatives should visit schools, attend community meetings and place advertisements in the local newspaper, on radio stations and in social media with the intention of creating awareness amongst the residents about the importance of the tourism industry and how they benefit from and form a part of it. A sense of pride should also be fostered within the community by informing residents that people travel from across the world to scuba dive in the MPA. Furthermore, policymakers should work on creating policies that will protect and enhance the opportunities and duties of stakeholders to better regulate the SDTS. Also, the local tourism offices or MPA should set up a forum where representatives of all stakeholders can meet and discuss their interests. Such discussions should take place on a regular basis to avoid possible miscommunication or misperceptions among stakeholders.

According to the social exchange theory, if the residents do not perceive benefits from the scuba diving industry, they may not lend their support to it - without the support of this vital stakeholder, the STDS and MPA will not be sustainable and might even be unsuccessful.

When comparing differences in the perceptions of residents regarding whether they partake in scuba diving or not, and whether they are aware of the scuba diving industry in the MPA, or not, the sixth finding became apparent. It was found that when residents partake in or are aware of the scuba diving industry, they perceive the impact generated by the industry as more positive towards their community and their personal lives. This finding supports other findings made in this study and by various other authors (Gursoy et al., 2002; Kuvan \& Akan, 2005; Mowforth \& Munt, 2016; Saayman, 2012; Williams \& Lawson, 2001) which shows the importance of communication and participation of stakeholders.

The last finding was that the importance of taking the perceptions of both the scuba diving industry and the residents into consideration collectively, instead of examining only one stakeholder at a time. By examining two or more groups of stakeholders, it allows one to not only measure the social impacts of an industry but to also reveal other gaps in understanding that might assist in making more informed strategic management decisions towards a more sustainable STDS.

\section{Conclusions}

This paper builds on the research by Lucrezi et al. (2017), Markanonatou et al. (2016) and the earlier work by Solmona and Verandi (2001) by examining the levels of communication and cooperation among two stakeholders within the STDS of the Portofino MPA. This was done by measuring and comparing opinions and perceptions between dive operators in the Liguria district. The reasoning of the latter action was to determine why negativity from the residents towards the MPA, as well as the scuba diving industry, had been reported by various studies. Such studies revealed that residents did not participate in the planning and implementation of the MPA. It was decided to examine how relationships among the stakeholders were affected.

A lack of communication and cooperation among dive operators and residents, who are key stakeholders of the MPA and STDS, was observed. This generated misperceptions and negative sentiment among the key stakeholders in the SDTS towards one another and the MPA. It was suggested that this situation be eased through facilitation by the area's tourism offices, which should increase 
awareness through domestic marketing efforts as well as community education. According to literature, the Portofino MPA with its STDS is not sustainable in its current state. It is therefore essential that communication channels among all stakeholders should exist. If the residents understand the importance of the MPA and the scuba diving industry for the success of their communities and also participate in the planning and management of the MPA, it will foster their vital support for both. This research corroborates research that has revealed the importance of acknowledging all stakeholders and placing value on them. The importance of communication and cooperation among stakeholders was also revealed.

This study contributes to literature regarding the importance of the residents as stakeholders in the tourism industry in aspects such as planning and execution of tourism developments. Furthermore, it builds upon the literature of the specific case study area, the Portofino MPA, and might assist in creating a more sustainable SDTS in this area if recommendations are implemented. This research also contributes towards the practical management of this specific MPA, and should also be used in the planning and management of other MPAs globally as it serves as proof of the negative impacts that a lack of communication and participation can generate within SDTSs.

It is recommended that future research on similar communities be done through qualitative research as to provide a more indepth understanding of the residents' perceptions. Furthermore, similar research should be repeated longitudinally to determine if there are any improvements or degradation in the communication and cooperation between the researched key stakeholders of the PMPA. Such research should also be conducted on other, similar SDTSs in different locations around the world to add to current literature and ensure the sustainability of the scuba diving industry.

Lastly, the authors acknowledge the limitations of this study, in that a small sample size was achieved and that the results are not generalizable, and only applicable to the Liguria District in Italy.

\section{Acknowledgements}

The authors wish to extend their gratitude to all the diving charter businesses/schools who participated in the interviews, as well as the residents who completed the questionnaires. Then also an exceptional thanks to Serena Lucrezi, Eliana Ferretti, Ubaldo Pantaleo, Martinette Kruger for assisting with the distribution of the questionnaire. Also, for Serena Lucrezi for helping with the interviews and acting as interpreter. This study was funded by the Green Bubbles RISE project, H2020-MSCA-RISE-2014. The project has received funding from the European Union Horizon 2020 research and innovation programme under the Marie Sklodowska-Curie grant agreement No. 643712. This paper reflects only the authors' view. The Research Executive Agency is not responsible for any use that may be made of the information it contains.

\section{References}

Abidin, S. Z. Z., \& Mohamed, B. (2014). A review of SCUBA diving impacts and implication for coral reefs conservation and tourism management. SHS Web of Conferences, 12. URL: https://www.shsconferences.org/articles/shsconf/pdf/2014/ 09/shsconf 4ictr2014 01093.pdf

(Accessed on 20.08.2017).

Area Marina Protetta Portofino. (2016). Subacquea. URL: http:// www.portofino amp.it/it/subacquea.html (Accessed on 18.08.2017).

Creswell, J.W., \& Clark, V.L.P. (2011). Designing and conduction: Mixed methods research. $3^{\text {rd }}$ ed. Los Angeles, CA: SAGE.

Deery, M., Jago, L., \& Fredline, L. (2012). Rethinking social impacts of tourism research: A new research agenda. Tourism Management, 33(1), 64-73.

Dimmock, K., Cummins, T., \& Musa, G. (2013). The business of scuba diving tourism. In G. Musa, D., \& Dimmock, K. (eds.) (2017). Scuba diving tourism. Abingdon, Oxon: Routledge, 161-174.

Dimmock, K. \& Musa, G. (2015). Scuba Diving Tourism System: A framework for 
collaborative management and sustainability. Marine Policy, 54, 52-58.

Fabinyi, M. (2008). Dive tourism, fishing and marine protected areas in the Calamianes Islands, Phillippines. Marine Policy, 32(6), 898-904.

Fennell, D. A. (2015). Ecotourism. New York, NY: Routledge.

Freeman, R. E. (2014). Strategic management: a stakeholder approach. San Barnardino, CA: University of Minnesota Press.

Garrod, B., \& Wilson, C. J. (2003). Marine ecotourism: Issues and experiences. Aspects of Tourism: 7. Cleveland: Channel View Publications.

Geldenhuys, L., Van Der Merwe, P., \& Slabbert, E. (2014). Who is the scuba diver who visits Sodwana Bay and why? South African Journal of Research in Sport, Physical Education and Recreation, 62(2), 90-104.

Godfrey, K., \& Clarke, J. (2007). Tourism development handbook: A practical approach to planning and marketing. London: Cengage Learning EMEA.

Gursoy, D., Jurowski, C., \& Uysal, M. (2002). Resident attitudes: A structural modelling approach. Annals of Tourism Research, 29, 79-105.

Hall, C. M. (2001). Trends in ocean and coastal tourism: the end of the last frontier? Ocean and Coastal Management, 44(1), 601-618.

Hall, D. R., \& Richards, G. (2006). Tourism and sustainable community development. London: Routledge.

Higgens-Desboilles, F. (2006). More than an "industry": The forgotten power of tourism as a social force. Tourism Management, 27(6), 1192-1208.

Hillmer-Pegram, K. C. (2014). Economies of tourism destinations. Understanding the resilience of dive tourism to complex change. Tourism Geographies, 16(4), 598-614.

Hritz, N., \& Ross, C. (2010). The perceived impacts of sport tourism: An urban host community perspective. Journal of Sport Management, 24, 119-138.

Inskeep, E. (1994). National and regional tourism planning. In A World Tourism Organization (WTO) Publication. London: Routledge.
Jackson, A. J. (2006). Ameliorating the negative impacts of tourism: A Caribbean perspective. International journal of contemporary hospitality management, 18(7), 574-582.

Jennings, S. (2004). Coastal tourism and shoreline management. Annals of Tourism Research, 31(4), 899-922.

Jurowski, C., \& Gursoy, D. (2004). Distance effects on residents' attitudes towards tourism. Annals of Tourism Research, 31(2), 296-312.

Kreag, G. (2007). The impact of tourism. URL: http://www.seagrant.umn.edu/downloads/t 13.pdf (Accessed on 19.10.2017).

Kuvan, Y., \& Akan, P. (2005). Residents' attitudes toward general and forest-related impacts of tourism: the case of Belek, Antalya. Tourism Management, 26(5), 691-706.

Lucrezi, S., Milanese, M., Markantonatou, V., Cerrano, C., Sarà, A., Palma, M., \& Saayman, M. (2017). Scuba diving tourism systems and sustainability: Perceptions by the scuba divining industry in two Marine Protected Areas. Tourism Management, 59, 385-403.

Markantonatou, V., Noguera-Méndez, P., \& Semitiel-García, M. (2016). Social networks and information flow: building the ground for collaborative marine conservation planning in Portofino Marine Protected Area (MPA). Ocean and Coastal Management, 120, 29-38.

Mascia, M. B., Claus, A., \& Naidoo, R. (2010). Impact of Marine Protected Areas on Fishing Communities. Conservation Biology, 24(5), 1424-1429.

Mason, P. (2015). Tourism impacts, planning and management. London: Routeledge.

Mmmpa.eu. (2017). MPA Portofino. URL: http://www.mmmpa.eu/POR-MPA.asp (Accessed on 10.10.2017).

Moschella, P. S., Laane, R. P. W. M., Back, S., Behrendt, H., Bendoricchio, G., Georgiou, S., Herman, P. M. J., Lindeboom, H., Skourtous, M. S., Tett, P., Voss, M., \& Windhorst, W. (2005). Group report: Methodologies to support implementation of the Water Framework Directive. In Vermaat, J. E., Bouwer, L. M., Salomons, W., \& Turner, R. K. (eds.), Managing 
present and future. Springer, Berlin, pp. 137-152.

Maree, K. (2016). First steps in Research. Pretoria: Van Schaik.

Moskwa, E. C. (2012). Exploring place attachment: An underwater perspective. Tourism in Marine Environments, 8(1), 3346.

Mowforth, M., \& Munt, I. (2016). Tourism and sustainability: Development, globalisation and new tourism in the Third World. New York, NY: Routledge.

Muganda, M., Sirima, A., \& Ezra, P. M. (2013). The role of local communities in tourism development: Grassroots perspectives from Tanzania. Journal of Human Ecology, 41, 53-66.

PADI. 2016. World Corporate Statistics 2016: Data for 2010-2015. URL: https://www. padi.com/sites/default/files/documents/abo ut-padi/statistics/PADI 2016 WW Statistics.pdf (Accessed on 09.10.2017).

Paddock, R. C. (2006). Forked Tongues Rule. Los Angeles Times, Column One, July, 5.

Park, D. B., Lee, K. W., Choi, H. S., \& Yoon, Y. (2012). Factors influencing social capital in rural tourism communities in South Korea. Tourism Management, 33(6), 1511-1520.

Pretty, J. (1995). The many interpretations of participation. In Focus, 16(6), 4-5.

Raj, R., \& Musgrave, J. (2009). Event management and sustainability. Cambridge, MA: CABI.

Roberts, C. M., Bohnsack, J. A., Gell, F., Hawkins, J. P., \& Goodridge, R. (2001). Effects of marine reserves on adjacent fisheries. Science 294, 1920-1923.
Saayman, M. (2013). En route with tourism. Cape Town: Juta and Company.

Salmona, P., \& Verardi, D. (2001). The marine protected area of Portofino, Italy: a difficult balance. Ocean \& Coastal Management, 44(1-2), 39-60.

Scholtz, M., \& Slabbert, E. (2015). The relevance of the tangible and intangible social impacts of tourism on selected South African communities. Journal of Tourism and Cultural Change, 14, 107128.

Scholtz, M., \& Slabbert, E. (2017). Tourism is not just about the Money: A Comparison of Three South African Communities. African Journal of Hospitality, Tourism and Leisure, 6(3), 1-21.

Simmons, D. G. (1994). Community participation in tourism planning. Tourism Management, 15, 98-108.

Slabbert, E., \& Viviers, P. A. (2013). The impacts of a major South African arts festival: The voices of the community. African Journal of Physical, Health Education, Recreation and Dance, 19(3), 623-638.

Tosun, C. (2000). Limits to Community participation in the tourism development process in developing countries. Tourism Management, 21(6), 613-633.

Tosun, C. (2006). Expected nature of community participation in tourism development. Tourism management, 27(3), 493-504.

Williams, J., \& Lawson, R. 2001. Community issues and resident opinions of tourism. Annals of Tourism Research, 28(2), 269290. 